\title{
Marijuana Toxicity: Heavy Metal Exposure Through State-Sponsored Access to "la Fee Verte"
}

\author{
David V Gauvin*, Zachary J Zimmermann, Joshua Yoder and Rachel Tapp
}

Department of Neurobehavioral Sciences, MPI Research, 54943 North Main Street, Mattawan, MI 49071, USA

\begin{abstract}
Federally unregulated, Marijuana Growth Organizations (MGOs) have now provided a path to exposures to the neurotoxicity of heavy metals. The lack of US Food and Drug Administration (FDA) and US Environmental Protection Agency (EPA) testing and oversight of the MGOs now threatens the public health. Agribusiness and botany experts proclaim the value of cannabis as a perfect rotating plant for phytoremediation programs to help scavenge heavy metals from soils prior to seeding the land for food product. Cannabis has a high affinity for soil contaminants without affecting its own heartiness. However, "legal" marijuana plots have burgeoned in the "Emerald Triangle" of Northern California, Oregon and Washington. According to the FDA's toxicology program, the largest sources of heavy metals (HMs) are the environments surrounding abandoned or active mines. The history of gold, platinum, coal, and copper mining in these grow areas now threatens the end-user; the plants ability to "scrub the earth" of these highly toxic HMs provides main stream smoke contamination to the consumer. Published reports of cannabis users showing hearing loss and neurological changes to temporal lobe structures involved in audition as well as learning and memory. The apoptotic cascade of cytotoxic events initiated by heavy metals is linked to the progression of Alzheimer's and Parkinson's disease, as well as hearing loss related to brain stem and temporal lobe neurotoxicity.
\end{abstract}

Keywords: Intracerebroventricular; Intraventricular; FDA; Cannabis; Drug administration; Central nervous system; Regulatory; Neurotoxicity

\section{Introduction}

One of the first international collaborative efforts in drug control focused on restricted access to absinthe - also known as the "green fairy" (la fée verte). Absinthe is an alcohol distillate from wormwood that contains thujone. Thujone, a major component of the absinthe drink is neurotoxic, although the current view rather downgrades its risk to humans [1]. However, thujone is still restricted by the US FDA (21 CFR $\$ 172.510$, dated April 1, 2017). Marijuana represents the new green fairy sponsored for its medical utility.

\section{Experimental}

\section{Cannabis}

The medical panacea Marijuana is a Schedule I controlled substance under international treaty commitments [2] and codified (as federal law) by the U.S. Congress into the Comprehensive Drug Abuse and Control Act of 1973 ([3] also known as the Controlled Substances Act $[\mathrm{CSA}])$. In spite of the popular press, medicine is not defined by public vote, community councils, or state legislatures. Under the Food, Drug and Cosmetic Act, the only legally-competent authority to determine whether any substance is a "medicine" is the executive branch cabinet post position of the Department of Health and Human Services (DHHS), and through a Memo of Understanding (MOU), the Commissioner of the Food and Drug Administration. Only after a thorough review of both nonclinical and clinical data it is the FDA alone, that fulfils the legislative mandate to determine what is and what isn't medicine in this country. Because of the heterogeneous nature of a botanical drug and possible uncertainty about its active constituents, one of the critical issues that the FDA is mandated by legal statutes to address is the assurance that the therapeutic effect for each marketed drug product batches are consistent. Each formulation on the market is required to meet strict control standards.

In general, the FDA ensures therapeutic consistency by a "totality of the evidence" approach, including the following considerations:

1) Botanical raw material control (e.g., agricultural practice and collection).
2) Quality control by chemical test (s) (e.g., analytical tests such as spectroscopic and/or chromatographic methods that capture the active or chemical constituents of a botanical drug substance).

3) Manufacturing (agricultural) control (e.g., process validation).

4) Biological assay (e.g., a biological assay that reflects the drug's known or intended mechanism of action) and clinical data (for details regarding use of clinical data in ensuring therapeutic consistency.

There are statutory thresholds for the formal adoption of any new molecular entity to be accepted as medicine in the US. In 2018 marijuana is not medicine, it remains in Schedule I of the Controlled Substances Act as a hallucinogen with no approved medical use in the US.

There are five criteria that define "medical use", all of which must be satisfied:

(1) the drug's chemistry must be known and reproducible,

(2) there must be adequate safety studies,

(3) there must be adequate and well-controlled studies proving efficacy,

(4) the drug must be accepted by qualified experts, and

(5) the scientific evidence must be widely available. In 2017 the National Academies of Science published an update on their previous position on therapeutic cannabis. In the most recent review of the literature the NAS team concluded that "there is substantial evidence

*Corresponding author: David V Gauvin, Director, Department of Neurobehaviora Sciences, MPI Research, 54943 North Main Street, Mattawan, MI 49071, USA, Tel: +1269-668-3336; E-mail: david.gauvin@mpiresearch.com

Received March 11, 2018; Accepted March 22, 2018; Published April 01, 2018

Citation: Gauvin DV, Zimmermann ZJ, Yoder J, Tapp R (2018) Marijuana Toxicity: Heavy Metal Exposure Through State-Sponsored Access to "la Fee Verte". Pharmaceut Reg Affairs 7: 202. doi: 10.4172/2167-7689.1000202

Copyright: $\odot 2018$ Gauvin DV, et al. This is an open-access article distributed under the terms of the Creative Commons Attribution License, which permits unrestricted use, distribution, and reproduction in any medium, provided the original author and source are credited. 
that cannabis is an effective treatment for chronic pain in adults", however in their review the committee summarized their findings as:

The majority of studies on pain cited in Whiting et al. (2015) evaluated nabiximols outside the United States. In their review, the committee found that only a handful of studies have evaluated the use of cannabis in the United States, and all of them evaluated cannabis in flower form provided by the National Institute on Drug Abuse that was either vaporized or smoked. In contrast, many of the cannabis products that are sold in state-regulated markets bear little resemblance to the products that are available for research at the federal level in the United States (p. 89).

Thus, while the use of cannabis for the treatment of pain is supported by well-controlled clinical trials as reviewed above, very little is known about the efficacy, dose, routes of administration, or side effects of commonly used and commercially available cannabis products in the United States. Given the ubiquitous availability of cannabis products in much of the nation, more research is needed on the various forms, routes of administration, and combination of cannabinoids (p. 90)

The National Academies of Science [4] has chosen their words poorly. While their review acknowledges that their conclusion was based on a majority of studies conducted outside of the U.S. using the cannabinoid combination product, Nabiximols (Sativex"), an extract of cannabis containing tetrahydrocannabinol and cannabidiol, approved as a botanical drug in the United Kingdom in 2010, their conclusion was not a tacit approval of cannabis (the plant material), per se. The gelatin encapsulated product, THC in sesame-seed oil (Marinol"), is already approved in the US. Sativex" and Marinol" are not cannabis (as legally defined), they are constituent elements of the plant. Analogously, morphine and codeine, are natural alkaloids of opium, but opium is not an approved medicine under international or national statutes. This is important to note because when Dr. Donald Abrams [5], one of the review board members of the NAS team, published his recent 2018 notice of result summaries of the NAS review, he modified the conclusion to state "the report concluded that there was conclusive or substantial evidence that Cannabis or cannabinoids are effective for the treatment of pain in adults". The disjunctive statement of the Abrams report is not identical to the Academies' conclusion statement. Sativex ${ }^{\mathrm{Tw}}$ and Marinol ${ }^{\mathrm{Tm}}$ are not cannabis - they are constituent elements of the marijuana plant, much like thebaine, morphine and codeine in the opium poppy (papaver somniferum). This use of mixed metaphors in the cannabis debate is common and is used to confuse the message.

As of this date (2018) there is insufficient valid, reliable and legallydefensible scientific data to support a conclusion of therapeutic use of marijuana plant under the Food, Drug and Cosmetic Act (FDandCA) in the United States. In spite of the popular press, there remains a paucity of credible well-controlled randomized clinical trial data to demonstrate that marijuana meets the legitimate, statutory and legallydefensible criteria as an analgesic, anticonvulsant, antispasmodic, antianxiety, or any other effective intervention in any disease process that would meet the standard "litmus test" for new drug application licensure in the U.S. It is, however, a naturally occurring intoxicant.

There is a three-pronged definition of substances placed in Schedule I control status:

1) the drug or substance has a high potential for abuse;

2) the drug or other substance has no currently accepted medical use in treatment in the United States;

3) there is a lack of accepted safety for use of the drug or other substance under medical supervision.
Many proponents of "medical marijuana" base their objections to drug control status based solely on Item \#3. While the statutory control of marijuana is based, in part, on the lack of accepted safety (no danger), proponents often make the false claim that marijuana is not "dangerous" and is "safer" than alcohol (non-controlled substance) and is not attributed to many documented cause-of-deaths (i.e. LD50's in animals). The marijuana proponents seem to restrict their definition of "dangerous" to "lethality" or "deaths". Under the law, the term "danger" is generally defined through property law statutes and is different than the common connotation of the American vernacular. Water is not inherently dangerous, but spilled water on the floor of department store meets the litmus test for public danger. Clothes detergent packets are not inherently dangerous; allowing access to the packet for easy consumption by children meets the litmus test of "dangerous situation" that may further jeopardize the adults' parental rights.

A dangerous instrument is any substance which, under the circumstances in which it is used, attempted to be used, or threatened to be used, is highly capable of creating a substantial risk of injury when it is used in a reasonably foreseeable manner. Generally, a dangerous substance is a risk that children or young adults cannot appreciate or avoid due to their immaturity or ignorance (is not known) or appreciated by the adults of legal age. For example, heroin (3,6-diacetylmorphine) is a Schedule I drug in the US, but it is a pharmacologically potent analgesic opioid (therapeutic use) in other countries. However, heroin does not have acceptable medical use in the US, based solely on the lack of the full appreciation for the pharmacology of the drug, its rate of entry into the CNS, its dependence producing potential, its actual illicit abuse patterns, as well as its abuse liability characteristics. Pharmaceutical-grade heroin lacks the adulterants of street/illicit supplies and is pharmaceutically pure; it still has no medical use in the US. There is limited knowledge of these pharmacological attributes in the general population, and certainly limited appreciation for the full impact of these critical factors when or if the drug was taken outside the scope of medical supervision. Therefore, heroin is a dangerous drug and has Schedule I control status.

In contrast to the stability and purity of pharmaceutical manufactured heroin, marijuana is an unstable weed, it is an entourage substance. Marijuana contains over 650 other chemical substances beside Tetrahydrocannabinol (THC). The concentrations and presence of these chemicals vary between growth cycles and, more importantly, vary between plants from the same stock source. The concentrations of THC and the approximate 64 other cannabinoids in the plant is not controlled by genetics. There is an almost universal belief that unlike tobacco, marijuana smoke is benign [6,7]. The threat to human health is based, in part, on the generally held naïve belief of its safety, its long history of actual abuse, and the total lack of awareness or control of the phytotoxicity of other chemicals contained within the plant materials.

Proof of drug-induced toxicity does not have to be established by demonstrating that marijuana administration is directly cytotoxic or "causes cancer". The neuronal insult may be activated by inhalation of marijuana smoke that produces injury via a second or tertiary pathway. There is precedent set to show that normal brain circuitry can produce a "built in" pattern of selective vulnerability that is likely to be important determinants of cell death (e.g. excitotoxic injuries, glutamate surge, etc.). With respect to this review, the danger of marijuana consumption includes the presence of Heavy Metals (HM) and their duplicitous roles in cytotoxicity. 
State-sponsored marijuana initiatives have spawned an agricultural boon in the number of legal and illegal Marijuana Growth Organizations (MGOs) that have been given unfettered access to grow, harvest and distribute a variety of cannabis plant materials with no knowledge of quality, integrity, or quantitative composition of what is being administered to human consumers. In the delusion of "compassionate care" many physicians' have been duped into a false sense of security with home-grown cultivars and MGO supplied "medicines" that are consumed without any federal regulatory control or oversight. Of great interest to drug regulators and environmental safety toxicologists is the report that medical marijuana supplies have been independently tested and found to contain rodenticide, herbicides, and pesticide residues. The link between environmental contaminants and marijuana toxicity is certainly not new. Forty years ago, Alpers [8] admonished that:

Intentional or unintentional exposure to environmental chemicals could enhance or inhibit the activity of hepatic mixed function oxidases that metabolise drugs and other foreign chemicals, as well as endogenous substrates such as steroid hormones. A major source of such exposure may be occupational. Exposure to the heavy metal, lead, has been shown to inhibit drug metabolism; whereas intensive exposure to chlorinated insecticides, and other halogenated hydrocarbons such as polychlorinated biphenyls, has been shown to enhance the metabolism of test drugs such as antipyrine and phenylbutazone.

In late 2017, an independent journalist, Lester Black reported that big recreational marijuana producers have swallowed up most of the green market, pushing out the small-scale growers of the black and medical markets. From January through September of 2017, Black [9] reported that the 10 largest farms in Washington harvested 16.79 of all the dry weight weed grown in the state, which is more than the share produced by the 500 smallest farms combined (13.12\%). The consolidation of cannabis farming will inevitability become a largescale agribusiness that will start to drive down production costs. According to Black [9], current regulations restrict growth plot size in the western states. Washington has expanded the maximum farm size from 30,000 square feet to 90,000 . California plans on capping farms at 1 acre, or 43,560 square feet, when the market first launches, however, there is no limit to the number of licenses each state registrant is allowed to own. With agribusinesses now involved the large-scale production and harvesting techniques now come into effect. Fertilizers, pesticides, insecticides, fungicides, miticides, and growth stimulators appear to be the norm - ganja growth is now "large farma" and there is no federal oversight. Cannabis is not a hybrid plant, it is an unstable weed.

Agricultural/industrial contaminants of cultivated marijuana should be a significant source of concern to the health status of marijuana users [10]. In 2016, Nathan Russo [11] reported 22 out of 26 marijuana samples were positive when analyzed for pesticide contamination in cultivation plots from the State of Washington (USA). Many harbored multiple contaminants attaining levels 10's of thousands of Parts Per Billion (ppb) and exceeding the upper limit of quantitation. These included 45 distinct agents from every class of insecticides, miticides, fungicides, synergists and growth regulators, including organophosphates and organochlorides. Cuypers et al. [12] reported finding pesticides in $64.3 \%$ of 72 cannabis plant samples from indoor growth plots and in $65.2 \%$ of 46 carbon filter cloth samples taken from the air supply of the fruticetum. Overall, 19 pesticides belonging to different chemical classes were identified in marijuana harvested for human consumption, including o-phenylphenol, bifenazate, cypermethrin, imidacloprid, propamocarb, propiconazole and tebuconazole, which are consistent with the commonly reported pesticides in the literature. In a 2015 report by Raber, Elzinga and
Kaplan [13] California grown patient-advocate or "medical" marijuana was submitted by the end users requesting analysis for contaminants. Thirty-three percent of all submitted samples were found to be contaminated with pesticides. The most commonly found pesticide in the California samples was paclobutrazol, a plant growth regulator. This is of great concern because this pesticide is not registered by the U.S. Environmental Protection Agency (EPA) for use on food crops. Sullivan et al., [14] have previously reported that up to $70 \%$ of paclobutrazol is transferred into the smoke stream. Two other pesticides found in the US samples were bifenthrin (a pyrathroid insecticide) and myclobutanil (a systemic fungicide). In 2015, myclobutanil was found in Coloradogrown marijuana by the Colorado Department of Agriculture (http:// www.coloradogreenlab.com/blog/eagle-20-and-myclobutanil-inthe-context-of-cannabis-cultivation-and-consumption). Aside from environmental chemical contamination the medical use of marijuana has been linked to other health threats associated with poor quality control standards during growth or harvest, such as aspergillosis [1517]. With a physician's signature on a prescription, state-approved medical marijuana may now be the new "la fée verte", the green fairy supplying toxic agrochemical residues or plant fungal contamination to dying and sick patients under the ruse of "compassionate care" - but the situation is more dire than this.

\section{Cannabis: The "Blessing" Can Be a Scurge}

Botanists have been touting the efficiency and benefits of certain plants and trees to the ecosystems by their ability to transfer elements from abiotic into biotic environments [18]. There are plants that accumulate excessive metals. The use of plants for environmental restoration is an emerging technology and the plants capable of accumulating higher levels of metals have been grown in the contaminated soils [19]. Large agribusinesses are interested in plant rotations that help to sustain development of healthy soils and that can decontaminate metal polluted air, soil, and water [20]. On one hand the metal extraction ability of plants is of great concern regarding a possible entrance into food chain but on the other hand, this ability of plants can be used as an alternative technology to remediate contaminated soils. Phytoextraction can be defined as the use of living plants to absorb and accumulate metals from the soil into the aerial parts, which are harvested with conventional agricultural methods [21]. By scheduled field rotations the phytoextraction capabilities of nonfood plants can "clean up" contaminated soils prior to planting of the food crops [22]. Phytoextraction then is a cost effective, environmental friendly technology used for cleaning of polluted soils to the advantage of food development. Cannabis has been found to be an exceptional phytoextractor.

All elements of the biosphere are adulterated by a variety of inorganic and organic pollutants as a result of man-made environmental activities such as mining. A variety of biological resources have been investigated and employed in attempts to clean up the metal polluted sites. These technologies have gained considerable momentum under-developed nations and are currently in the process of commercialization in the industrialized nations, as well [23-25]. Plant and plant-rotations designed to remove industrial/environmental pollutants from the environment are targeting the toxic effects of HM on the health of all living organisms, this is known as phytoremediation. Phyto-extraction of heavy metals from contaminated soils has the advantage of being a more economic in situ alternative to other forms of clean up and, more importantly, is a great advertising ploy for garnering public opinion and support to the agribusiness. The soil based heavy metals of interest to toxicologists are, at a minimum, iron $(\mathrm{Fe})$, zinc $(\mathrm{Zn})$, chromium $(\mathrm{Cr})$, lead $(\mathrm{Pb})$, nickel $(\mathrm{Ni})$, cadmium $(\mathrm{Cd})$ and arsenic $(\mathrm{As})$. 
Phytoextraction targets ecotoxicologically the most relevant soil fraction of these metals, i.e. the bioavailable fraction. HM extraction and accumulation by plants depends upon the species and the efficiency of absorption [26,27]. For example, plants on cadmium contaminated soil can absorb and accumulate cadmium due to its high mobility in the soil-plant system allowing its easy entrance into the food chain and causes toxic effects in animals [28,29]. A large number of factors control metal accumulation and bioavailability associated with soil and climatic conditions, plant genotype and agronomic management, including: active/passive transfer processes, sequestration and speciation, redox states, the type of plant root system and the response of plants to elements in relation to seasonal cycles [30].

In order to achieve rapid growth and high yield extensive fertilizers are applied to plants; fertilizers not only provide nutrients to plants but can also change the speciation and mobility of metals in soil [21]. Nitrogen, phosphorus and potassium are the most essential chemical fertilizers for growth of plants under both in vivo and in vitro conditions [31]. Ed Rosenthal [32], referred to as the "best-known marijuana horticulturists in America" (p. xiii), describes the demand for critical nutrients in the fertilizers will vary with the growing conditions and changes during the plant's life cycle. Marijuana uses more nitrogen during the vegetative stage (prior to flowering) when compared to later stages and uses more phosphorous as the flower begins followed by increased demand for potassium after fertilization to aid flower formation and seed production ([32], page 157). HM uptake into vegetables and grain increases with application of chemical fertilizers [33-36]. Agribusiness use of large plot production of recreational or medical marijuana sets the stage for a public health crisis based on its "natural" chemical cleaning properties of soil HMs.

\section{Source of Cannabis Hm Contamination}

The activity of wild weeds growing in metal-contaminated soil has shown hyper-accumulation of HMs and hence proving their phytoremediation mettle [37]. A number of studies have now been carried out on marijuana that provides convincing evidence that the weed is an active accumulator for HMs such as lead, cadmium, magnesium, copper, chromium, and cobalt. The sources of these HMs are the result of human (anthrogenic) activities such as mining, smelting, sewage sludge and automobile emissions [38-45].

The U.S. Department of Interior, Geological Survey has reported that most of the mercury used in gold recovery in California was obtained from mercury deposits on the west side of California's Central Valley. Total mercury production in California between 1850 and 1981 was more than $220,000,000$ pounds (https://pubs.usgs.gov/ fs $/ 2005 / 3014 /$ ). The government reports that most of this mercury was exported around the Pacific Rim or transported to Nevada and other western states (i.e., Colorado, New Mexico). In relations to HM residues in soil $12 \%(26,000,000 \mathrm{lb})$ of the mercury mined in California was used for gold recovery in California, lending to its relative high contribution to the total eco-burden of soil-based HMs [46].

Three western states in the US lead the country in the agricultural growth, processing, and sales of marijuana for recreational and therapeutic use: California, Oregon, and Washington. Among the world's largest producers of illicit opium, the United Nations Office of Drug Control (UNODC) and other law enforcement agencies commonly refer to areas of the mid-East (Iran, Pakistan, and Afghanistan) and Asia (Burma, Thailand, Viet Nam and Laos) as the "Golden Crescent" and "Golden Triangle", respectively. Based on the astronomical MGOs located in Mendocino, Humboldt, and Trinity Counties of northern California this hot bed of licit and illicit marijuana plots is now referred to as the "Emerald Triangle".
The mining industry, past and present, in Californian, Oregon, Washington and Colorado are expansive. The automobile emission residues are consistent with the astronomical traffic patterns of the western states. These two man-made sources are the leading cause of environmental HM pollution products in soil and water. HMs have been deposited by sludge water run-off, excavated earth materials dumped as mine depth increased, and by the presence of US military bases and nuclear test facilities that capriciously deposited radioactive (cobalt, uranium, strontium, cesium, etc.) and inert HMs from weapon testing and training (lead, chromium, nickel, etc.) in the same geographical areas as mines and automobiles [47].

The crop productivity of the agribusiness in 3rd world countries has been advanced by the use of marijuana (industrial hemp) to hyperaccumulate industrial waste products to convert wastelands into cultivated land, especially the area contaminated with heavy metal pollution (lead, copper, zinc, cobalt, and cadmium) [48,49].

Marijuana is a hyper-accumulator for cobalt. Cobalt and compounds that release cobalt ions in vivo, which would now include marijuana, have been recently listed as carcinogenic by the American Association for Cancer Research [50]. As a constituent element of marijuana grown in contaminated soils of northern California, Oregon and Washington, cobalt represents one of the hidden toxic dangers to the state-sponsored medicine programs. In the California medicinal cannabis distribution system quality control is not mandated and dispensary systems are more likely to submit the highest quality product for any required analysis. Therefore, advertised stock qualities from state-sponsored dispensaries are influenced by sample submission bias and the reported data might not reflect the entire product range of toxic substances contained in the state-sponsored supply of medical marijuana. According to Raber, Elzinger and Kepler [13] many of California's medical cannabis patients are susceptible to the toxic effects of these elements due to their compromised immune systems or hepatic illnesses. This is tantamount to state-sponsored medical fraud.

Another HM, cadmium (Cd) is also known to be one of the most phytotoxic of the soil-based HMs [24,51]. Marijuana is one of the best phytoextractors for Cd [49]. Except for roots, the highest concentrations of $\mathrm{Cd}$ are found in the marijuana leaves, whereas the lowest are typically observed in seeds [52]. Marijuana has been found to be highly cadmium-tolerant and very useful in bioaccumulation of cadmium with its superior ability to accumulate cadmium in the smokeable harvest. Marijuana does have a high capacity for phytostabilization and is tolerant to contaminants. The importance to public health risk is marijuana's ability to accumulate metals along with stabilization of contaminated areas like the "Emerald Triangle" and, unlike most plants used in bioremediation, it offers additional end uses. The extraction capability for heavy metals from the soil makes marijuana an ideal soil phytoremediation agent. The property of marijuana to scavenge cadmium from contaminated soils of northern California, Oregon and Washington should focus the attention of public health regulators to the potential negative effects that could be caused due to potential metal accumulation on the health of patients for whom the "medical marijuana" is grown.

Cd concentrations of up to $72 \mathrm{mg} / \mathrm{kg}$ (soil) have been reported to have no negative effect on germination of marijuana, and exposures of up to $100 \mathrm{ppm}$, has no significant effects on the morphological growth of the marijuana plant. The highest concentration of cadmium tolerance has been shown in the roots of marijuana at a maximum $830 \mathrm{mg} / \mathrm{kg}$ without affecting the growth of the plant [53]. Plants generally do not accumulate elements beyond near-term metabolic needs, which are 
small ranging from 10 to $15 \mathrm{ppm}$ of most trace elements [54]. Hyperaccumulators like marijuana are exceptions to the rule and have been reported to accumulate toxic metals much beyond the trace-element limits up to the levels of thousands of ppm. During the phytomediation process soil contamination is transported from roots to shoots, which are harvested, causing contamination to be removed while leaving the original soil undisturbed [54].

The high concentrations of HM accumulation achieved in marijuana cannot be explained exclusively by passive ion uptake. The hyper-accumulatory properties of marijuana are dependent upon several factors. Polychelatin formation is one of the important basic factors for the scavenging of HMs, especially in the context of $\mathrm{Cd}$ tolerance [55]. Technically, polyamines strengthen the defense response of plants and modulate their activity against diverse environmental stressors including metal toxicity [56], and oxidative stress [57]. The other class of significantly notable chelating compounds in marijuana is metallothioneins as shown in Table 1.

Malik et al. [58] has reported that marijuana has a high translocation rate for another $\mathrm{HM}$, zinc, with an estimated translocation factor value of $>1.0$. This translocation factor promotes the accumulation of $\mathrm{Zn}$ into the smokable parts of marijuana comparable to other HMs. Malik et al. [58] report that accumulation of zinc is maximal in shoots and it shows marijuana's full hyper-accumulating property by storing the HMs in their shoots (compare root concentrations relative to shoot concentrations of zinc). Juknat et al. [59] has reported that the non-psychoactive element of smoked marijuana, cannabidiol (CBD) upregulates the expression of the mRNAs for metallothionein 2 (Mt2), $\mathrm{N}$-myc-downstream regulated gene 1 and matrix metalloproteinase 23 in vivo. CBD upregulates the zinc transporters: ZnT1/Slc30a1 and Zip4/Slc39a4. Interestingly, Juknat et al. [59] report that CBD also downregulates the expression of the mRNA for the zinc transporter Zip10/Slc39a10 as well as for the zinc finger protein 472 . These genes, ZnT1, Mt2 and the zinc transporters ZIPs are known to function together to control the intracellular zinc concentrations in vivo.

Bernhoft [60] has described the metabolic pathway for cadmium after absorption. Cd is transported bound to a sulfhydryl groupcontaining protein like metallothionein. One-third of the inhaled $\mathrm{Cd}$ goes to liver, one-third goes to kidneys, and the residual $40 \%$ is distributed in other tissues of the body. Critically important to the discussion of neurotoxicity of cadmium is the realization that any absorbed cadmium is excreted primarily in the urine, but because daily excretion is only about $0.01 \%$ of the total body burden, the biological half-life is about 25 years. For the cadmium that does enter the blood stream, the half-life has been estimated at 75 to 128 days, but this halflife primarily represents deposition in organs, not clearance from the body. Consequently, blood, hair, and urine $\mathrm{Cd}$ levels are poor surrogates for body burden and chiefly reflect recent exposure, as is also true with the other HMs. While the presence of the HMs in marijuana may or

\begin{tabular}{|c|c|c|}
\hline & \multicolumn{2}{|c|}{ Concentration } \\
\hline Heavy metal & Roots & Shoots \\
\hline Lead & mg/kg Dried weight & mg/kg Dried weight \\
\hline Copper & 29 & 30 \\
\hline Zinc & 29 & 18.2 \\
\hline Nickel & 27 & 43.9 \\
\hline Cadmium & 13.6 & 11.3 \\
\hline Chromium & 24.7 & 14.8 \\
\hline
\end{tabular}

Table 1: Heavy metal accumulation in marijuana expressed in $\mathrm{mg} / \mathrm{kg}$ of dry material. may not contribute to a statistically significant increase in total body burden for each metal, the risk assessment required for FDA approval must also focus on more local changes to cellular environments of the mouth, throat, and lung with respect to direct cytotoxic insults and the astronomical duration of tissue exposures long after the "buzz" of intoxication. In regard to CDC risk assessments, the lifetime cancer mortality risk coefficients have been calculated for nearly all radionuclides, including cadmium. The coefficients for inhalation are greater than for ingestion. For marijuana and tobacco, the toxicity value for estimating the risk of cancer from inhalation exposure is called a Unit Risk (UR), which is an estimate of the chance that a person will get cancer from continuous exposure to a chemical in air at a concentration of 1 milligram per cubic meter $\left(\mathrm{mg} / \mathrm{m}^{3}\right)$. The UR for cancer risk for inhaled cadmium from smoked marijuana is $1.8 \mathrm{mg} / \mathrm{m}^{3}$.

The inhalation of HMs may or may not support a role of smoked marijuana as a cancer risk [61], but toxic metals may also contribute to non-cancer health risks such as cardiovascular diseases [62-64], and other maladies such as Chronic Obstructive Pulmonary Disease (COPD) and smoking related interstitial lung disease that are characterized by sensitization, chronic inflammation, or tissue remodeling [65-68]. Wang et al., [6] has clearly demonstrated that even 1 minute exposure to second hand marijuana smoke substantially impairs endothelial function in rats for at least 90 minutes. These effects were greater than comparable exposure to tobacco second hand smoke and did not rely on the presence of cannabinoids in the main stream smoke.

Repetitive inhalations of unfiltered marijuana smoke directly expose the oral and pulmonary epithelium to relatively high concentrations of marijuana-based condensates plus HMs. Small particles and soluble toxic substances can be directly absorbed into epithelial and interstitial tissues prior to being passed into the general circulation. So, while systemic (blood, plasma, or urine) concentrations may not reflect statistically significant changes in total body burden to these HMs selective local cells can go through changes resulting in pathological cytotoxicities [69]. For example, smoke cadmium is a Group 1 human carcinogen and is cytotoxic. Marijuana is one of the best phytoextractors of soil-based cadmium and is one of the highest concentrations of HMs in the dry material. When smoked it induces proinflammatory cytokines as a carcinogen, and is a substance that causes disease in many body tissues including lungs, liver and kidneys.

\section{Pyrolysis of Hms in The Preferred Method of Dose Administration}

Smoking marijuana and inhalation of second-hand smoke are associated with inflammation, cellular atypia, and molecular dysregulation of the tracheobronchial epithelium. While marijuana smoke shares many components in common with tobacco, it also contains a high concentration of $\Delta 9$-Tetrahydrocannabinol (THC) and CBD. The inhaled cannabinoids have been shown to induce a time- and concentration-dependent decrease in cell viability, ATP level, and mitochondrial membrane potentials [70]. Sarafian et al. [70] reported acute changes $(24 \mathrm{~h})$ in the expression of mRNA for caspase-8, catalase, Bax, early growth response-1, cytochrome P4501A1 (CYP1A1), metallothionein 1A, PLAB, and heat shock factor 1 (HSF1) - all biomarkers for apoptosis (programmed cell death). The presence of zinc, cobalt, and cadmium, and their own direct effects on antioxidant and anti-inflammatory processes may interact with these cannabinoid-related direct cytoxic effects. As stated above, $1 / 3$ of these HMs accumulate in the kidney, often times 30 to 60 -fold greater than in the lungs $[71,72]$. 
Most of the consumers of recreational and medical cannabis use it or prefer it by the inhalation/smoking route. Smoke chemistry has been predominantly investigated in tobacco products but a 10 -year old report by Moir et al. [73] highlighted the qualitatively similar carcinogenic chemicals contained within both tobacco and marijuana smoke [74-76]. Using two methods, the International Organization for Standardization's method, ISO 3308, and their own Health Canada method tobacco and marijuana cigarettes were analysed. The HMs contained in both smoked product included: mercury, cadmium, lead, chromium, nickel, arsenic, and selenium. Interestingly, marijuana smoke contained significantly more hydrogen cyanide, aromatic amines, ammonia, NO (nitric oxide, nitric monoxide) and NOx (a generic term for the nitrogen oxides, [ for example, $\mathrm{NO}_{2}$ ] which are major contributors to air pollution. $\mathrm{NO}, \mathrm{NOx}$, cyanide and aromatic amines were 3 to 5 times greater in marijuana smoke compared to tobacco and ammonia concentrations were 20 times higher than tobacco. Quantitatively, there were significantly lower HMs concentrations in marijuana smoke condensates, however, this was due to the marijuana supply used by Moir et al. [73] in their study.

Unlike the tobacco supply the bulk marijuana used in the Moir et al., [73] study was purchased from a Canadian hydroponic research laboratory. With no soil-based HMs to be extracted during the growth cycle of the marijuana, it was the liquid fertilizers used in the hydroponic systems that were attributed as the cause of the differential ammonia, NO, NOx and aromatic amines reported in their study. Normal soil grown tobacco was compared to soil-less marijuana in this study. The soil-less growth medium of the marijuana supply required water-soluble hydroponic vegetable fertilizers which contain nitrogen in the form of nitrate and ammoniacal nitrogen. While Moir et al. [73] confirmed the presences of similar HMs in tobacco and marijuana the study does not provide reliable data on the quantitative concentration of HMs of their comparisons in this study.

As discussed above, aside from cadmium, exposure to inhaled smoke from the unfiltered marijuana cigarette also includes arsensic, aluminum, chromium, copper, lead, mercury. The oral, nasal and pulmonary epithelium, being the first "wet tissues" to come into direct contact with airborne compounds of marijuana smoke serve as the "ground zero" for toxic insult [77]. A non-sensory function of the olfactory and gustatory systems is the active transport by these primary sensory neurons that may represent a mechanism of entry into the central nervous system for compounds that are normally excluded by the blood-brain barrier. Sunderman [78] has shown that aluminum, cadmium, cobalt, lead, manganese, nickel and zinc can pass via olfactory receptor neurons from the nasal lumen through the cribriform plate to the olfactory bulb. Some of these HMs (eg, $\mathrm{Mn}, \mathrm{Ni}, \mathrm{Zn}$ ) can cross synapses in the olfactory bulb and migrate via secondary olfactory neurons to distant nuclei of the brain. According to Sunderman [78], transport of the HMs via olfactory axons can occur rapidly, within hours or a few days (eg, $\mathrm{Mn}$ ), or slowly over days or weeks (eg, Ni). The olfactory bulb tends to accumulate certain metals (eg, $\mathrm{Al}, \mathrm{Bi}, \mathrm{Cu}, \mathrm{Mn}, \mathrm{Zn}$ ) with greater avidity than other regions of the brain [79].

Henriksson and Tjälve [80] has shown that intranasal instillation of mercury into the right nostrils of rats resulted in much higher levels of the metal in the right olfactory bulbs than in the left ones. At the side of the application of mercury there was also a labeling of the olfactory nerve bundles projecting to the olfactory bulbs as well as in the olfactory nerve-fibers constituting the olfactory nerve layer of the bulbs, which was not seen on the opposite side. These results show that the local application of HMs in smoked condensate, like mercury, can accumulate in the glomerular layer of the olfactory bulbs (CNS penetration). These data further suggest that movement of the HMs along the olfactory axons to their terminal parts in the glomeruli are not the result of vascular uptake from the mucosa. Radioactive labeling of mercury was also discernable in the external plexiform layer of the CNS, indicating that HMs also leave the terminal arborizations of the axons in the glomeruli. Tjälve et al. [81] have shown similar active transport of the HM, manganese, in rats by an initial uptake of the metal in the olfactory bulbs. The HM was then seen to migrate via secondary and tertiary olfactory pathways and via further connections into most parts of the brain and also to the spinal cord. On the other hand, cadmium instillation into the nasal mucosa resulted in uptake of the metal into the anterior parts of the olfactory bulbs but not into other areas of the brain. Manganese is a neurotoxic metal which in man can induce an extrapyramidal motor system dysfunction. Tjälve et al. [81] proposed that the neurotoxicity of inhaled manganese is related to an uptake of the metal directly into the brain via the olfactory pathways. In this way manganese can circumvent the systemic vasculature and the impermeable blood-brain barrier and gain direct access to the central nervous system.

Similar transneuronal active transportation pathways have been shown for another HM found in marijuana smoke, cobalt, by Persson, Henriksson, and Tjälve [82]. Local instillation of nasal cobalt accumulated in the olfactory nerve layer and the terminals of the primary olfactory neurons in the glomerular layer of the bulb. In addition, cobalt migration into the interior of the bulbs was followed by deposits into the anterior parts of the olfactory cortex, indicating that these HMs may be able to leave the terminals of the primary olfactory neurons. Memory deficits have been observed among human workers exposed to cobalt via inhalation, and it must be considered that cobalt in mainstream marijuana smoke may be neurotoxic, as well. Public health risk assessments must include the proposal that inhaled HMs (as entourage chemicals of smoked medical marijuana) is deposited in the oral, nasal and pulmonary passages and that released HMs, after uptake into the brain via nonvascular pathways, may cause the neurotoxicity associated with the attention, learning, and memory deficits in human marijuana users.

\section{Results and Discussion}

\section{Hms Oxidative stress and toxicity}

The systemic and cellular toxicity of metals varies with the electrical charge of the cation and the local concentrations that comes in contact with the cell membranes. These represent "local cellular events" that occur prior to the metals entering the blood stream. For example, $\mathrm{Pb}$ (lead) causes inhibition of specific enzymes involved in heme biosynthesis and causes replacement of iron in the heme by zinc which, in turn, generates a nonfunctional zinc protporphyrine [83]. In some instances, functional living cells respond to high concentrations of HMs, such as cadmium, zinc and copper, by synthesizing a family of proteins call metallothioneins in an attempt to sequester the cations [84]. As stated above, excess zinc is cytotoxic. Zinc, copper, cadmium, and lead form mercaptides. The presence of mercaptides rapidly induce the synthesis of metalothionein by local cells, in an attempt to chelate them and avert any direct cell death from the surfeit of these oxidizing metals. These HMs then compete for functional iron (ferritin) that interfere with the normal iron storage and mobilization needed for healthy cell systems. Ferritin transcriptional and translational regulation is also involved with cellular interactions with cadmium, manganese, arsenic and aluminum [85-90]. Price and Joshi and Joshi et al. $[91,92]$ suggested that it is ferritin that is the primary detoxification response to HMs. 
It is the pivotal role of cellular iron (heme) in dealing with all of these HMs administered with each inhalation ("toke") of the marijuana smoke. The characteristic post-inspiratory pause (breath hold) that is not present in tobacco smokers also sets the stage for HM exposure that initiates cytotoxicity through free radical production and cell death. But, what about the toxic effects of HMs that do not utilize the vascular system for transport into the CNS?

According to Bernhoft [60], cadmium causes oxidative stress and histologically visible membrane disturbances in the central nervous system. The presence of cadmium has also been linked to reductions in acetylcholinesterase activity, increase in oxidative stress markers, depletion of glutathione, superoxide dismutase 2, and other antioxidants, as well as depletions of anti-oxidant concentration of catalase, glutathione peroxidase, and glutathione-S-transferase [93]. These changes have apparently led to apoptosis of cortical cells in the central nervous system, possibly due to phosphorylation of calcium/ calmodulin dependent protein kinase II [94]. Cd can also inhibit influx through calcium channels [95].

\section{Signs of neurotoxicity associated with marijuana use}

The risk assessment plan for any drug application submitted for license approval must be based on contemporary, scientifically valid, reliable and legally defensible data. In any federally mandated health safety assessment review on marijuana conducted by the CDC, FDA, NIDA or DEA the data from low potency marijuana of the 1960s to 2000 have minimal relevance with respect to the current true yield of THC and CBD concentrations on today's market. Marijuana samples are generally found to contain $>12 \%$ THC and solvent extracted hash oils (butane-hash oils) have been found to contain up to $90 \%$ THC (cf) [96]. Aside from these relatively astronomical cannabinoid content characteristics, risk assessments cannot diminish or deny the basic characteristics of the marijuana plant as a phyto-extractor of soilbased HMs. Therefore, FDA must take into account the entourage of other toxic chemicals, like HMS, that are delivered in the palliative smoked product harvested from current geographical locations of the agribusiness source of supplies to state-sponsored dispensaries, i.e., the "Emerald Triangle" [96].

"Clean" marijuana is not benign to CNS injury. In 2014, Skosnik et al. [97] reported finding a significant reduction in EEG "high power gamma wavebands" in cannabis users who smoked marijuana at least once per week over the last four weeks with no other drug use over the past 3 months. EEG gamma wavebands ( 30 to $80 \mathrm{~Hz}$ ) are believed to play a key role in sensory data registration and the integration and binding of perceptual features of the environment that represent basic associative learning processes and a measure of conscious awareness. These data were similar to previous studies of marijuana smokers that utilized evoked and steady-state EEGs [98-100]. These changes in relative power of high frequency wavebands in the EEGs represent a neural correlate for various higher perceptual and cognitive processes involved in learning and memory and are consistent with the current view that cannabinoids play a general role in the generation and maintenance of neural synchrony in temporal lobe functions related to learning and memory functions.

In 2011, Winton-Brown and colleagues [101] reported that THC (oral administered capsules) increased self-reported states of anxiety, intoxication, and positive psychotic symptoms. Additionally, these authors reported bilateral decreases in activation of temporal cortices during auditory processing as well as decreases in activation of visual cortices during processing of visual information using fMRI. During basic information processing of auditory signals, THC reduced activation in the superior temporal gyri and middle temporal gyri, insula, and supramarginal gyri and the right inferior frontal gyri as well as the left cerebellum. During visual information processing tasks, THC reduced activation in the extrastriate visual cortex, and increased activation in the lingual and middle occipital gyri corresponding to the primary visual cortex in the left hemisphere. These areas of the brain are critically linked to learning and memory functions. O'Leary et al. [102-105] used PET scans to demonstrate reduced blood flow in these temporal, occipital and frontal cortices, as well as the cerebellum. Hippocampal, Wernicke's and Broca's areas are located in these general areas of the human brain and implicate a role of THC in affecting these language centers, as well. These regional blood flow changes and decreased activity certainly correlate with the loss of high gamma powerbands recorded from surface-based EEG electrodes. The question now arises as to the full impact of HMs delivered to these same areas with THC from smoked medical marijuana grown in the Emerald Triangle. While previous data showed a direct neural basis for THC-induced changes in these CNS areas - those studies that administered THC were devoid of soil-based HMs. The presence of oxidative stress-induced apoptosis associated with the transport of HMs to these centers of learning and memory have the potential pose a stronger threat to the health of the patients to whom they are medically prescribed. Humans with elevated blood or urine cadmium concentrations demonstrate decreased measures of attention and memory impairments [106], as well as a significant decrease in lowfrequency hearing thresholds [107]. In nonclinical toxicity studies, rats with high urinary cadmium also exhibit decreased learning ability. The significant threat to human health from inhaled marijuana smoke that contains $\mathrm{Cd}, \mathrm{Co}, \mathrm{Ni}, \mathrm{Zn}$ is further demonstrated by the findings that intranasal cadmium exposures destroys olfactory nerve function in the rat (direct neuro/cytotoxicity: Czarnecky et al., [108]. Cadmium also raises the frequency of spontaneous cortical electrical activity in the rodent and lengthens the latency of sensory-evoked potentials. These impairments are without detectable Cd brain deposits [93]. Given the ubiquity of $\mathrm{Cd}$ in the current large-growth environments of the west coast states that grow a preponderance of all medical marijuana prescribed in the US, public health policy makers must take account of the comorbidity of $\mathrm{Cd}$ exposures to the recent cultivation of high potency THC- and CBD-based medicines and the other harmful chemicals found in the hybridized weeds of 2018.

We are at the brink of a public health crisis with state-sponsored poisoning of clinical patients prescribed medical cannabis by health care professionals. Primum non nocere - first do no harm! And Caveat emptor-buyer beware! There are no safety guarantees to the patients who assume a safe pharmaceutical grade product is being prescribed by their health care professional and they certainly are not guaranteed safe and effective plant product from the state-sponsored dispensary that fills that prescription for the unwitting ill patient. The statesponsored supply of marijuana in California, Colorado, Washington and Oregon for medical or recreational use has a high probability of being contaminated with toxic HMs through the basic botanical and genetically-based phytoremediation features of their "wonder plant".

Contemporary public health risk assessments for medical and recreational marijuana must take into account:

1) the current high potency THC containing product now on store shelves of the state-sponsored dispensaries,

2) the neurotoxic exposures from rodenticides, insecticides, miticides, fungicides, synergists and growth regulators being used in the current federally-unregulated agricultural production and harvesting of the botanical, and 
3) the entourage environmental HM contaminants that result from the basic chemo-attractive affinity of the marijuana plant itself.

The legend that the emperor "Nero played the fiddle while Rome burned " describes the current federal regulatory environment of both the FDA and EPA - two related regulatory agencies of the US government that have left the "killing fields" of medical marijuana unsupervised, unregulated, and without federal oversight while proficient proponents of legal intoxication have bred astronomical THC containing plant materials that have been planted in soil plots located in areas of the US with a long and rich history of land mining and the associated environmental chemical contaminants known to kill both animals and man.

The FDA can no longer close its eyes on this state-sponsored threat to human health. The patient population of the US has a constitutional guaranteed right of access to safe and effective food and drug supplies in this country. The FDA-based risk assessment of medical and recreational marijuana must include the standard medical reviews conducted by the EPA with respect to environmental contaminants and trace elements allowed for food consumption in the US. First, and foremost the health and security of the public must be maintained by federal authority. The need to reduce the harm caused by drugs must be focused on preventing their use, by treating those who abuse them, and by limiting the damage they cause to the individual and society. Regardless of any relative implication for therapeutic targets for constituent elements of the plant material (i.e., CBD) there is no statutory requirement to remove control status from the plant which contains many other elements related to intoxication (THC) and toxicity (i.e., HMS, smoke condensation products). The unstable characteristic of natural chemical constituents of marijuana, betweenand within-cultivars, does not provide confidence in the quality of the substance being sold in state-sponsored dispensaries. It is the constitutional responsibility of federal government to ensure that drug policy is evidence-based, not the result of political considerations or ideological preferences.

The dichotomy of prohibition vs legalization is a misnomer. Under standard health risk assessments such a confrontation is too simplistic for scientific-based decisions regarding human health policy in the US. From a public health perspective, it is more accurate to refer to the divergence between popular vote, state-wide initiatives, or common folk-lore and the surmounting evidence of valid, reliable and legallydefensible data conducted independently and without intentional sampling or design bias in the regulatory approval process of new medicines.

\section{Conclusion}

In 2018, the intentional genetic manipulations of astronomical THC concentrations in raw plant materials (approximating 30\% THC), the publically-available process-derived retail plant products that contain THC concentrations that far exceed the scientifically tested thresholds for safety (butane hash oil: $90 \%$ THC), as well as the direct cytotoxic effects of other chemicals included in the plant materials harvested from state-sponsored MGO plots meets and exceeds the international standard definition of "dangerous drug". For the health and safety of the American population in 2018, the preponderance of valid, reliable and legally-defensible scientific data on marijuana dictates that the plant and its intoxicants must remain in Schedule I of the Controlled Substances Act. All US drug regulatory agencies (FDA, EPA, DEA, DOJ) and the Executive Branch's Office of National Drug Control Policy (ONDSCP) should now reject the "Cole Memorandum" of 2013, a Department of Justice initiative to restrict and bind-the-hands of federal agencies involvement in state initiatives that intentionally violated and superseded federal and international laws regarding schedule control status of marijuana [109].

\section{References}

1. Pelkonen $\mathrm{O}$, Abass K, Wiesner $\mathrm{J}$ (2013) Thujone and thujone-containing herbal medicinal and botanical products: Toxicological assessment. Regul Toxicol Pharmacol 65: 100-107.

2. https://www.unodc.org/pdf/convention_1961_en.pdf

3. https://www.deadiversion.usdoj.gov/21cfr/21usc/index.html

4. National Academies of Sciences, Engineering and Medicine (2017) The health effects of Cannabis and Cannabinoids: The current state of evidence and recommendations for research. Washington, DC: The National Academies Press.

5. Abrams DJ (2018) The therapeutic effects of Cannabis and cannabinoids: An update from the National Academies of Sciences, Engineering and Medicine report. Eur J Intern Med 49: 11-17.

6. Wang X, Derakhshandeh R, Liu J, Narayan S, Nabavizadeh P, et al. (2016) One minute of marijuana secondhand smoke exposure substantially impairs vascular endothelial function. J Am Heart Assoc 5: e003858.

7. http://www.monitoringthefuture.org/pubs/monographs/vol1_2001.pdf

8. Alpers AP (1978) Research review. Interactions between environmental chemicals and drug biotransformation in man. Clin Pharmacokinet 3: 462-477.

9. https://fivethirtyeight.com/features/legal-weed-isnt-the-boon-small-businessesthought-it-would-be/

10. Fraser HS, Tibbits RC (1983) Variation in response to drugs: Part II. Environmental and nutritional variables. West Indian Med J 32: 66-74.

11. Maccarrone M (2016) Pesticide contamination of cannabis in the legal market 26th Annual Symposium of the International Cannabinoid Research Society, Bukovina, Poland. Research Triangle Park: NC, Poland.

12. Cuypers E, Vanhove W, Gotink J, Bonneure A, Van Damme P, et al. (2017) The use of pesticides in Belgian illicit indoor cannabis plantations. Forensic Sc Int 277: 59-65.

13. Raber JC, Elzinga S, Kaplan C (2015) Understanding dabs: Contamination concerns of cannabis concentrates and cannabinoid transfer during the act of dabbing. J Toxicol Sci 40: 797-803

14. Sullivan N, Elzinga S, Raber JC (2013) Determination of pesticide residues in cannabis smoke. J Toxicol

15. Marks WH, Florence L, Lieberman J, Chapman P, Howard D, et al. (1996) Successfully treated invasive pulmonary aspergillosis associated with smoking marijuana in a renal transplant recipient. Transplantation 61: 1771-1774.

16. Ko JP, Kim DH, Shepard JA (2002) Pulmonary aspergillosis in an immunocompetent patient. J Thorac Imaging 17: 70-73.

17. Cescon DW, Page AV, Richardson S, Moore MJ, Boerner S, et al. (2008) Invasive pulmonary aspergillosis associated with marijuana: use in a man with colorectal cancer. J Clin Oncology 26: 2214-2215.

18. Irshid, M, Ahmad, S, Pervez A, Inoue M (2015) Phytoaccumulation of heavy metals in natural plants thriving on wastewater effluent at Hattar Industrial Estate, Pakistan. Intern J Phytoremed 17: 154-158.

19. Lasat MM (2002) Phytoextraction of toxic metals: A review of biological mechanisms. J Environ Qual 31: 109-120.

20. Wenzel WW, Bunkowski M, Puschenreiter M, Horak O (2003) Rhizosphere characteristics of indigenously growing nickel hyperaccumulator and excluder plants on serpentine soil. Environ Poll. 123: 131-138.

21. Li NY, Fu QL, Zhuang P, Guo B, Zou B, et al. (2012) Effect of fertilizers on Cd uptake of Amaranthus hypochondriacus, a high biomass, fast growing and easily cultivated potential Cd hyperaccumulator. Int J Phytorem 14: 162-173.

22. Ahmad A, Hadi F, Ali N (2015) Effective phytoextraction of Cadmium (Cd) with increasing concentration of total phenolics and free proline in Cannabis sativa (L) plant under various treatments of fertilizers, Plant growth regulators and sodium salt. Internat J Phytoremed 17: 56-65.

23. Salt DE, Smith RD, Raskin L (1998) Phytoremediation. Ann Rev Plant Phys Plant Mol Biol 49: 643-668. 
24. Salt DE, Blaylock M, Kumar PB, Dushenkov V, Ensley BD, et al. (1995) Phytoremediation: A novel strategy for the removal of toxic metals from the environment using plants. Biotech 13: 468-474

25. Prasad MNV, Freitas HMD (2003) Metal hyperaccumulation in plants: Biodiversity prospecting for phytoremediation technology. Electron J Biotech 6: 285-321.

26. Rattan RK, Datta SP, Chhonkar PK, Suribabu K, Singh AK (2005) Long term impact of irrigation with sewage effluents on heavy metal content in soils, crop and ground water- A case study. Agric Ecosys Environ 10: 310-322.

27. Chunilall V, Kindness A, Jonnalagadda SB (2005) Heavy metal uptake by two edible Amaranthus herbs grown on soils contaminated with lead, mercury, cadmium, and nickel. J Environ Sci Health B 40: 375-384.

28. Zadeh BM, Savaghebi-Firozabadi GR, Alikhani HA, Hosseini HM (2008) Effect of sunflower and Amaranthus culture and application of inoculants on phytoremediation of the soils contaminated with cadmium. Amer-Eurasian J Agric Environ Sci 4: 93-103

29. Nogawa G, Honda R, Kiod T, Tsuritani I, Yamada Y (1987) Limits to protect people eating cadmium in rice, based on epidermiological studies. Trace Subst Environ Health 21: 431-439.

30. Kabata-Pendias A, Pendias H (1984) Trace elements in soils and plants. Edn $1^{\text {st }}$, Boca Raton (FL): CRC Press, USA.

31. Johari S, KumarA (1992) Effect of Nitrogen, Phosphorous and Potassium on growth and bio crude yield of Euphorbia antisyphilitica. Ann Arid Zone 31: 313314

32. Rosenthal E (2010) Ed Rosenthal's marijuana grower's handbook. Oakland CA: Quick American Publishing.

33. He QB, Singh BR (1994a) Crop uptake of cadmium from phosphorus fertilizers: I. Yield and cadmium content. Water Air Soil Pollut 74: 251-265.

34. He QB, Singh BR (1994b) Crop uptake of Cadmium from phosphorus fertilisers II. Relationship with extractable soil cadmium. Water Air Soil Pollut 74: 267-280.

35. Singh BR, Myhr K (1998) Cadmium uptake by barley as affected by Cd sources and $\mathrm{pH}$ levels. Geoderma 84: 185-194.

36. Mandal A, Purakayastha TJ, Patra AK, Sanyal SK (2012) Phytoremediation of arsenic contaminated soil by Pteris vitata. Influence of phosphatic fertilizers and repeated harvests. Int J Phytorem 14: 978-995.

37. Girdhar M, Sharma NR, Rehman H, Kumar A, Mohan A (2014) Comparative assessment for hyperaccumulatory and phytoremediation capability of three wild weeds. 3 Biotech 4: 579-589.

38. Foy CD, Chaney RL, White MC (1978) The physiology of metal toxicity in plants. Annu Rev Plant Physiol 29: 511-566.

39. Chronopoulos J, Haidouti C, Chronopoulou-Sereli A, Massas I (1997) Variations in plant and soil lead and cadmium content in urban parks in Athens, Greece. Sci Total Environ 196: 91-98.

40. Prasad MNV (2004) Heavy Metal Stress in Plants: From Molecules to Ecosystems, 2nd edn. Berlin, Heidelberg: Springer Verlag.

41. Dahmani-Muller H, Van Oort F, Balabane M (2000) Strategies of heavy meta uptake by three plant species growing near a metal smelter. Environ Pollut 109: 231-238.

42. https://www.atsdr.cdc.gov/ToxProfiles/tp33-c1-b.pdf

43. United States Department of Health and Human Services (2011) Agency for Toxic Substances and Disease Registry (ATSDR). Division of Toxicology and Environmental Medicine Environmental Medicine and Educational Services. Case Studies in Environmental Medicine (CSEM). Cadmium Toxicity.

44. United States Department of Health and Human Services (2011) Agency for Toxic Substances and Disease Registry (ATSDR). Division of Toxicology and Environmental Medicine Environmental Medicine and Educational Services. Case Studies in Environmental Medicine (CSEM) ChromiumToxicity

45. Cempel M, Nikel G. (2006) Nickel: A review of its sources and environmental toxicology. Polish J Environ Stud 15: 375-382.

46. Alpers CN, Hunerlach MP, May JT, Hothem RL (2005) Mercury Contamination from Historical Gold Mining in California: Fact Sheet, U.S. Geological Survey.

47. Hoseini PS, Poursafa P, Moattar F, Amin MM, Rezaei AH (2012) Ability of phytoremediation for absorption of strontium and cesium from soils using Cannabis sativa. Int J Env Health Eng 1: 17.
48. Angelova V, Ivanova R, Delibaltova V, Ivanov K (2004) Bioaccumulation and distribution of heavy metals in fibre crops (flax, cotton and hemp). Ind Crops Prod 19: 197-205.

49. Shi G, Liu C, Cui M, Ma Y, Cai Q (2012) Cadmium tolerance and bioaccumulation of 18 hemp accessions. Appl Biochem Biotechnol 168: 163-173.

50. American Association for Cancer Research (2017) Carcinogens Report adds seven agents. Cancer Discov 7: 5 .

51. Prasad MNV (1995) Cadmium toxicity and tolerance in vascular plants. Environ Exp Bot 35: 525-545

52. Ivanova R, Angelova V, Delibaltova V, Ivanov K, Shamov D (2003) Accumulation of heavy metals in fibre crops flax, cotton and hemp. J Environ Prot Ecol 4: 31-38.

53. Linger $P$, Mussing J, Fisher $\mathrm{H}$, Kobert J (2002) Industrial hemp (Cannabis sativa L.) growing on heavy metal contaminated soil fibre quality and phytoremediation potential. Ind Crop Prod 16: 33-42.

54. United States Department of Energy (1994) Summary Report of a Workshop on Phytoremediation Research Needs, Mechanisms of plant uptake, translocation, and storage of toxic elements pp: 7-10.

55. Cobbett CS (2000) Phytochelatins and their roles in heavy metal detoxification Plant Physiol 123: 825-832.

56. Groppa MD, Benavides MP (2008) Polyamines and abiotic stress: Recent advances. Amino Acids 34: 35-45.

57. Rider JE, Hacker A, Mackintosh CA, Pegg AE, Woster PM, et al. (2007) Spermine and spermidine mediate protection against oxidative damage caused by hydrogen peroxide. Amino Acids 33: 231-240.

58. Malik RN, Husain SZ, Nazir I (2010) Heavy metal contamination and accumulation in soil and wild plant species from industrial area of Islamabad. Pak J Bot 42: 291-301.

59. Juknat A, Rimmerman N, Levy R, Vogel Z, Kozela E (2012) Cannabidiol affects the expression of genes involved in zinc homeostasis in BV-2 microglial cells. Neurochem Int 61: 923-930.

60. Bernhoft RA (2013) Cadmium Toxicity and Treatment. The Scientific World Journal 2013: 1-7.

61. Fowles J, Dybing E (2003) Application of toxicological risk assessment principles to the chemical constituents of cigarette smoke. Tobacco Contro 12: $424-430$.

62. Navas-Acien A, Selvin E, Sharrett AR, Calderon-Aranda E, Silbergeld E, et al. (2004) Lead, cadmium, smoking, and increased risk of peripheral arterial disease. Circulation 109: 3196-3201.

63. Navas-Acien A, Silbergeld EK, Sharrett R, Calderon-Aranda E, Selvin E, et al (2005) Metals in urine and peripheral arterial disease. Environ Hith Perspect 113: $164-169$.

64. Navas-Acien A, Silbergeld EK, Schwartz BS, Nachman K, Burke TA, et al (2005) Arsenic exposure and cardiovascular disease: A systematic review of the epidemiologic evidence. Am J Epidemiol 162: 1037-1049.

65. Attili AK, Kazerooni EA, Gross BH, Flaherty KR, Myers JL, et al. (2008) Smoking-related interstitial lung disease: radiologic-clinical-pathologic correlation. Radiographics 28: 1383-1396.

66. Washko GR, Hunninghake GM, Fernandez IE, Nishino M, Okajima Y, et al. (2011) Lung volumes and emphysema in smokers with interstitial lung abnormalities. NEJM 364: 897-906.

67. Pappas RS (2012) WHO TobReg: Report on the scientific basis of tobacco product regulation: 4 th report of a WHO study group. World Health Organization pp: 37-83.

68. Pappas RS (2011) Toxic elements in tobacco and in cigarette smoke: Inflammation and sensitization. Metallomics 3: 1181-1198.

69. Richter P, Faroon O, Pappas RS (2017) Cadmium and Cadmium/Zinc Ratios and Tobacco-Related Morbidities. Int J Environ Res Public Health 14: E1154.

70. Sarafian T, Habib N, Mao JT, Tsu IH, Yamamoto ML, et al. (2005) Gene expression changes in human small airway epithelial cells exposed to Delta 9-tetrahydrocannabinol. Toxicol Lett 158: 95-107.

71. Lewis GP, Jusko WJ, Coughlin LL, Hartz S (1972a) Cadmium accumulation in man: Influence of smoking, occupation, alcoholic habit, and disease. J Chronic Dis 25: 717-726. 
Citation: Gauvin DV, Zimmermann ZJ, Yoder J, Tapp R (2018) Marijuana Toxicity: Heavy Metal Exposure Through State-Sponsored Access to "la Fee Verte". Pharmaceut Reg Affairs 7: 202. doi: 10.4172/2167-7689.1000202

Page 10 of 10

72. Lewis GP, Coughlin LL, Jusko WJ, Hartz S (1972b) Contribution of cigarette smoking to cadmium accumulation in man. Lancet 299: 291-292.

73. Moir D, Rickert WS, Levasseur G, Larose Y, Maertens R, et al. (2008) A comparison of mainstream and sidestream marijuana and tobacco cigarette smoke produced under two machine smoking conditions. Chem Res Toxicol 21: 494-502.

74. Lee ML, Novotny M, Bartle KD (1976) Gas chromatography/mass spectrometric and nuclear magnetic resonance spectrometric studies of carcinogenic polynuclear aromatic hydrocarbons in tobacco and marijuana smoke condensates. Anal Chem 48: 405-416.

75. Watson SJ, Benson JA Jr, Joy JE (2000) Marijuana and medicine: Assessing the science base: a summary of the 1999 Institute of Medicine report. Arch Gen Psychiatry 57: 547-552.

76. Hoffmann D, Brunnermann KD, Gori GB, Wynder EL (1975) On the carcinogenicity of marijuana smoke. In: VC Runeckles, Edn, Recent Advances in Phytochemistry, Plenum Press, New York, USA. pp: 63-81.

77. Hastings $L$ (1990) Sensory neurotoxicology: Use of the olfactory system in the assessment of toxicity. Neurotoxicol Teratol 12: 455-459.

78. Sunderman FW (2002) Nasal toxicity, carcinogenicity and olfactory uptake of metals. Ann Clin Lab Sci 31: 3-24.

79. Tjälve H, Henriksson J (1999) Uptake of metals in the brain via olfactory pathways. Neuro-toxicology 20: 181-195.

80. Henriksson J, Tjälve H (1998) Uptake of inorganic mercury in the olfactory bulbs via olfactory pathways in rats. Environ Res 77: 130-140.

81. Tjälve H, Henriksson J, Tallkvist J, Larsson BS, Lindquist NG (1996) Uptake of manganese and cadmium from the nasal mucosa into the central nervous system via olfactory pathways in rats. Pharmacol Toxicol 79: 347-356.

82. Persson E, Henriksson J, Tjälve H (2003) Uptake of cobalt from the nasa mucosa into the brain via olfactory pathways in rats. Toxicol Lett 145: 19-27.

83. Jeslow MM (1980) Blood zinc and lead poisoning. In: JO Nrigau (ed) Zinc in the environment: Ecological cycling: Health effects, Wiley Interscience. USA pp: 171-181.

84. Kojima Y, Kagi JHR (1978) Metallothioneins. Trends Biochem Sci 3: 90-93.

85. Muller JP, Vedel M, Monnot MJ, Touzet N, Wegnez M (1991) Molecular cloning and expression of ferritin mRNA in heavy metal-poisoned Xenopus laevis cells. DNA-Cell Biol 10: 571-579.

86. Noda M, Yosuda M, Kitagawa M (1991) Iron as a possible aggravating facto for osteopathy in itai-itai disease, a disease associated with chronic cadmium intoxication. J Bone Miner Res 6: 245-255

87. Suarez N, Eriksson H (1993) Receptor-mediated endocytosis of a manganese complex of transferrin into neuroblastoma (SHSY5Y) cells in culture. J Neurochem 61: 127-131.

88. Guzzo A, Karatzios C, Diorio C, DuBow MS (1994) Metallothionein-II and ferritin $\mathrm{H}$ mRNA levels are increased in arsenite-exposed HeLa cells. Biochem Biophys Res Commun 205: 59-595.

89. Godbold DL, Fritz E, Hütermann A (1988) Aluminum toxicity and forest decline. Proc Natl Acad Sci USA 85: 3888-3892.

90. Crapper DR, Krishnan SS, Quittkat S (1976) Aluminum neurofibrillary degeneration and Alzheimer's disease. Brain 99: 67-80.

91. Price DJ, Joshi JG (1984) Ferritin: Protection of enzymatic activity against the inhibition by divalent metal ions in vitro. Toxicology 31: 151-163.
92. Joshi JG, Price DJ, Fleming J (1984) Ferrin and metal toxicity. In: $H$ Peeters (ed) Protides of Biological Fluids Elsmford, Pergamon Press, USA pp: 183-186

93. Shagirtha K, Muthumani M, Prabu SM (2011) Melatonin abrogates cadmium induced oxidative stress related neurotoxicity in rats. Eur Rev Med Pharmacoll Sci 15: 1039-1050.

94. Chen S, Xu Y, Xu B, Guo M (2011) CaMKII is involved in cadmium activation of MAPK and mTOR pathways leading to neuronal cell death. J Neurochem 119: 1108-1118.

95. Bodereau-Dubois B, List O, Calas-List D, Marques O, Communal PY, et al. (2012) Transmembrane potential polarization, calcium influx, and receptor conformational state modulate the sensitivity of the imidaclopridinsensitive neuronal insect nicotinic acetylcholine receptor to neonicotinoid insecticides. J Pharmacol Exp Ther 341: 326-339.

96. Gauvin DV (2018) A "budding" cannabis cottage-industry has set the stage for an impending public health crisis. Pharmaceut Regul Affairs 7: 1.

97. Skosnik PD, Krishnan GP, D'Souza DC, Hetrick WP, O'Donnell BF, et al. (2014) Disrupted Gamma-Band neural oscillations during coherent motion perception in heavy cannabis users. Neuropsychopharmacology 39: 3087-3099.

98. Edwards CR, Skosnik PD, Steinmetz AB, O'Donnell BF, Hetrick WP, et al. (2009) Sensory gating impairments in heavy cannabis users are associated with altered neural oscillations. Behav Neurosci 123: 894-904.

99. Skosnik PD, Krishnan GP, Aydt EE, Kuhlenshmidt HA, O'Donnell BF, et al. (2006) Psychophysio-logical evidence of altered neural synchronization in cannabis use: Relationship to schizotypy. Am J Psychiatry 163: 1798-1805.

100.Skosnik PD, D'Souza DC, Steinmetz AB, Edwards CR, Vollmer JM, et al. (2012) The effect of chronic cannabinoids on broadband EEG neura oscillations in humans. Neuropsychopharmacology 37: 2184-2193.

101. Winton-Brown TT, Allen P, Bhattacharyya S, Borgwardt SJ, FusarPoli P, et al. (2011) Modulation of auditory and visual processing by delta-9-Tetrahydrocannabinol and cannabidiol: An FMRI study. Neuropsychopharmacology 36: 1340-1348.

102. O'Leary DS, Block RI, Koeppel JA, Schultz SK, Magnotta VA, et al. (2007) Effects of smoking marijuana on focal attention and brain blood flow. Hum Psychopharmacol 22: 135-148.

103. O'Leary DS, Block RI, Turner BM, Koeppel J, Magnotta VA, et al. (2003) Marijuana alters the human cerebellar clock. Neuroreport 14: 1145-1151.

104. O'Leary DS, Block RI, Koeppel JA, Flaum M, Schultz SK, et al. (2002) Effects of smoking marijuana on brain perfusion and cognition. Neuropsychopharmacology 26: 802-816.

105. O'Leary DS, Block RI, Flaum M, Schultz SK, Boles Ponto LL, et al. (2000) Acute marijuana effects on rCBF and cognition: A PET study. Neuroreport 11: 3835-3841

106. Pacini S, Fiore MG, Magherini S, Morucci G, Branca JJ, et al. (2012) Could cadmium be responsible for some of the neurological signs and symptoms of Myalgic Encephalomyelitis/Chronic Fatigue Syndrome. Medical Hypotheses 79: 403-407.

107. Shargorodsky J, Curhan SG, Henderson E, Eavey R, Curhan GC, et al. (2011) Heavy metals exposure and hearing loss in US adolescents. Arch Otolaryngol Head Neck Surg 137: 1183-1189.

108. Czarnecki LA, Moberly AH, Turkel DJ, Rubinstein T, Pottackal J, et al. (2012) Functional rehabilitation of cadmium-induced neurotoxicity despite persisten peripheral pathophysiology in the olfactory system. Toxicol Sci 126: 534-544.

109. https://www.justice.gov/iso/opa/resources/3052013829132756857467.pdf 